\author{
ARTIGO \\ C. 10.22481/praxisedu.v15i33.5300
}

\title{
POR UM COTIDIANO ESCOLAR TRANSGRESSIVO: QUANDO CORPOS TRANS INTERROGAM AS PRÁTICAS CURRICULARES
}

\author{
BY A TRANSGRESSIVE SCHOOL DAILY: WHEN TRANS BODIES INTERROGATE \\ AS CURRICULAR PRACTICES
}

\section{POR UN COTIDIANO ESCOLAR TRANSGRESIVO: CUANDO CORPOS TRANS INTERROGAN LAS PRÁCTICAS CURRICULAR}

Paulo Melgaço da Silva Junior Universidade Federal do Rio de Janeiro - Brasil

Jonathan Fernandes de Aguiar Universidade Federal do Rio de Janeiro - Brasil

Maria Vitoria Campos Mamede Maia Universidade Federal do Rio de Janeiro - Brasil

\begin{abstract}
Resumo: O objetivo central deste artigo é discutir sobre os processos como as escolas estão buscando possibilidades para receber, acolher e integrar alunas/os trans*, dando respaldo para o desenvolvimento de suas lutas e busca pelo reconhecimento social. Para tal, realizamos uma pesquisa qualitativa e analisamos a percepção de duas pedagogas, duas estudantes do Ensino Médio público e uma estudante do ensino fundamental público. Defendemos que o reconhecimento das diferenças no cotidiano escolar é uma questão de justiça social, curricular e de direitos humanos.
\end{abstract}

Palavras-chave: Cotidiano escolar. Sexualidades. Transexuais na escola.

\begin{abstract}
The central article of this article is translated for processes in the transas, seeking schools to the development, hosted and transfer students / the trans *, giving support to the development of their fights and search by social recognition. Research of qualitative and analytical data of two pedagogues, two high school students and one public elementary school student. Defending the recognition of differences in school life is a matter of social justice, curriculum and human rights.
\end{abstract}

Keywords: School daily. Sexualities. Transsexuals at school.

Resumen: El objetivo central de este artículo es discutir sobre los procesos como las escuelas están buscando posibilidades para recibir, acoger e integrar alumnas / os trans *, dando respaldo para el desarrollo de sus luchas y búsqueda por el reconocimiento social. Para ello, realizamos una investigación cualitativa y analizamos la percepción de dos pedagogas, dos estudiantes de la Enseñanza Media pública y una estudiante de la enseñanza fundamental pública. Defendemos que el reconocimiento de las diferencias en el cotidiano escolar es una cuestión de justicia social, curricular y de derechos humanos. 
Palabras clave: Cotidiano escolar. Sexualidades. Transexuales en la escuela.

\section{Introdução}

O objetivo central deste artigo é discutir sobre os processos como as escolas estão buscando possibilidades para receber, acolher e integrar alunas/os trans ${ }^{* 1}$ dando respaldo para o desenvolvimento de suas lutas e busca pelo reconhecimento social. Para tal, analisamos a percepção de duas pedagogas, duas estudantes do Ensino Médio público e uma estudante do ensino fundamental público. Defendemos que o reconhecimento das diferenças no cotidiano escolar é uma questão de justiça social, curricular e de direitos humanos. Nesta perspectiva, buscamos, ao longo deste texto, potencializar presenças, investigar e discutir práticas curriculares que, apesar de ainda tímidas, estão investindo na valorização das diferenças e na aplicação das leis que reconhecem os direitos sociais de sujeitos até então invisibilizados ou subalternizados em nossa sociedade.

Tais objetivos descritos acima dialogam com os estudos realizados pelos autores desta pesquisa por defender que a escola deve ser uma das instâncias de socialização e troca de conhecimento entre sujeitos, promovendo processos inclusivos, sendo o lúdico uma das alternativas para o desenvolvimento da subjetividade de cada indivíduo em suas diversas especificidades de gênero, cor, raça, etnia, sexo e deficiência (AGUIAR; MAIA, 2018; SILVA JUNIOR; MAIA; IVENICKI 2018).

Em articulação com os objetivos mencionados no parágrafo acima, este trabalho pretende discutir práticas curriculares, estratégias pedagógicas de professores/as que atuam em escolas públicas que se preocupam com a valorização das diferenças como um direito social de qualquer cidadão. Neste caso, tal estudo pretende aprofundar uma lacuna apresentada por Almeida (2016) e publicada no Jornal Diário de Cuiabá:

O Brasil concentra $82 \%$ da evasão escolar de travestis e transgêneros. A informação é do defensor público João Paulo Carvalho Dias que é presidente da Comissão de Diversidade Sexual da Ordem dos Advogados do Brasil e membro conselheiro do Conselho Municipal de LGBT (Lésbicas, Gays, Bissexuais, Travestis, Transexuais e Transgêneros) em Cuiabá. Segundo a pesquisa "Juventudes na Escola, Sentidos e Buscas: Por que frequentam?",

\footnotetext{
${ }^{1}$ Destacamos que ao longo do texto utilizaremos o termo trans* com um asterisco (*) para contemplar a diversidade existente ao uso do termo trans*: travesti, transexuais, transgênero e entre outros.
} 
19,3\% dos alunos de escola pública não gostariam de ter um colega de classe travesti, homossexual, transexual ou transgênero. O estudo ouviu 8.283 estudantes na faixa de 15 a 29 anos no ano letivo de 2013. Entre os entrevistados, $7,1 \%$ não queria ter travestis como colegas de classe. Homossexuais (5,3\%), transexuais $(4,4 \%)$ e transgêneros $(2,5 \%)$ (ALMEIDA, 2016).

Como vimos, as escolas ainda são um dos mais perversos lugares para que um/uma estudante - cujo desejo sexual fuja à matriz heterossexual compulsória — possa assumir sua sexualidade (BRITZMAN, 1996, 2001; SULLIVAN, 1996). Esse espaço é ainda mais perverso se a criança for negra, pois ela sofre dupla rejeição: pela sexualidade e pela raça; e, se ainda for mulher, pelo gênero. Essa violência acontece contra o menino afeminado, a menina masculinizada e também contra os/as homossexuais de maneira geral. Este fenômeno de exclusão é um reflexo do heterossexismo exacerbado, isto é, a visão de que toda sociedade tem que ser heterossexual, mostrando como somos socializados dentro de um regime de “terrorismo cultural” (MISKOLCI, 2012).

Miskolci (2012, p.33) escreve que o terrorismo cultural "é um nome que busca ressaltar a maneira como opera socialmente o heterossexismo, fazendo do medo da violência a forma mais eficiente de imposição da sexualidade compulsória”. Segundo Moita Lopes (2012, p.9), embora as instituições escolares sejam espaços fundamentais para a "construção da vida social", porque nelas os/as estudantes podem "se expor a outras construções sociais sobre quem é ou pode ser", elas em sua grande maioria perpetuam com enunciados que preservam percepções e hierarquizações sobre gênero, sexualidade, raça, etnia de caráter conservador. Assim, legitimando às vezes o preconceito, a discriminação e reiterando atos agressivos, violentos por compreender que o outro é diferente e não se enquadra nas regras heteronomativas.

Para ilustrar os inúmeros enunciados que reforçam o conservadorismo e o preconceito, apresentamos algumas falas que foram anotadas por um dos autores deste texto em uma formação continuada para professores/as da Educação Básica, no ano de 2017, no município de Itaperuna: "escola não é lugar para falar sobre gênero e sexualidade. Escola é lugar de ensino e aprendizagem. Falar sobre sexo é coisa da família”. Em seguida, ao questionar o grupo de professores/as que participavam da formação sobre inclusão "como propor a inclusão de pessoas trans* no espaço escolar?" O mesmo professor que falou que gênero não se discute na escola, associando Educação Sexual com ensino de sexo, relata: "essa pessoa não chega à escola. Pra que falar sobre?” Assim repetimos: pra que falar sobre? Pra quê? E 
nossas vozes ecoam: para que nossas escolas sejam instituições inclusivas que tenham como princípio a convivência, o respeito pelo outro que nos apresenta aos nossos olhos como diferente. A escola é plural (SANTOS, 2003, 2008) até porque se acreditamos que a escola é para todos, logo ela deve discutir gênero, raça, etnia, sexualidade, deficiências para romper com estereótipos e qualquer tipo de preconceito que exclua pessoas do processo de escolarização. Com isso, a escola é para todos e não deve existir exclusão.

Após este breve cenário sobre a instituição escolar e a maneira como a escola enfrenta as discussões sobre gênero em relação aos/ás diversos/as interlocutores/as - professores/as, estudantes e gestores/as, para atender ao objetivo central deste artigo iremos analisar como a escola tem pensado e construído mecanismos de reconhecimento das diversas identidades de gênero principalmente das pessoas trans*, possibilitando processos inclusivos no ambiente escolar. Neste sentido, esta pesquisa é descrita como qualitativa (CANEN; IVENICKI, 2016) do tipo estudo de caso (ANDRÉ, 2005; GIL, 2009), cujos sujeitos são²: duas (2) Pedagogas: "Flávia" e "Antônia", que atuam em escolas públicas do município de Duque de Caxias no Ensino Fundamental, na modalidade de Educação de Jovens e Adultos - EJA; duas (2) estudantes do Ensino Médio: "Lexie" que pertence a uma instituição pública estadual de Belford Roxo e "Rachel” é estudante de uma instituição pública federal do Rio de Janeiro, e, uma (1) estudante do ensino fundamental, na modalidade de Educação de Jovens e Adultos EJA: "Safira". Os instrumentos utilizados para o levantamento de dados da pesquisa aqui efetuada foram: entrevista semiestruturada, anotações no diário de bordo de conversas informais e observação do cotidiano escolar realizados em diversos momentos de 2018.

Este artigo possui a seguinte estruturação para as próximas seções. Em um primeiro momento realizamos uma reflexão sobre as transexualidades. Logo a seguir, tematizamos os conceitos de justiça social e justiça curricular. Na terceira seção apresentamos as leis que legitimam a presença de corpos trans* nas escolas. A metodologia, os sujeitos, resultados e análises são apresentados e discutidos na seção transgredindo o cotidiano escolar. E por fim as considerações finais.

\section{Uma breve reflexão sobre transexualidades}

De acordo com Oliveira (2018) as experiências de pessoas trans* na sociedade brasileira passaram a ser temas de pesquisas acadêmicas com mais frequência a partir da

\footnotetext{
${ }^{2}$ Destacamos que todos os nomes aqui listados são fictícios.
} 
década de 1990. Contudo, foi a partir dos anos 2000 que estas passaram a ter uma maior visibilidade e despontaram como tema central em pesquisas brasileiras.

Ressaltamos que o termo "trans*” é utilizado para identificar aqueles sujeitos que transgridem as normas binárias do corpo e do gênero. Não é fácil discutir identidade trans*, mas é necessário inserir tal temática nos cotidianos escolares com a pretensão de eliminar os preconceitos e o esvaziamento de conhecimentos sobre este modelo de subjetividade.

A trans* e psicanalista Lanz (2015, p.121) afirma, em seus estudos, que "a pessoa descobre que é ao descobrir que não é o que a sociedade diz que ela é e exige que ela seja". Assim, a partir da biologia/fisiologia, quem nasce com pênis é considerado homem e quem nasce com órgão genital "vagina" é considerada uma mulher. No entanto, o nome transgênero é igualmente indicativo de gênero, mas não é algo definido a partir de um órgão genital préexistente. O/A trans* subverte as regras, fato que uma pessoa cisgênera ${ }^{3}$ acaba por não apresentar problemas ao se encaixar nas regras impostas pela sociedade. Por serem considerados/as transgressores/as de regras heteronormativas esses sujeitos acabam não tendo um lugar de pertencimento e nem de atendimento que estaria ligado a todos os âmbitos da vida humana: saúde, educação sociabilidades.

Nesta discussão, a letra "T", da sigla "LGBTIQ+", abriga diversas identidades, passando pelo transexual, travesti, transformista - "drag queen". Por este caminho, transgênero é uma circunstância sociopolítica de transgressão ou não conformidade com as normas estabelecidas do gênero como no caso dos cisgêneros (LANZ, 2015).

A luta pelos direitos das pessoas trans* no Brasil é atual. A legislação que garante os direitos das pessoas trans*é muito recente. Por exemplo, pesquisas desenvolvidas por Grossi, Oliveira e Silva (2017) destacam, que até os anos de 1990 no Brasil não existiam regulamentações em nível municipal, estadual que propusessem que os direitos das pessoas trans* fossem respeitados. Elas e eles eram tratadas/os de maneira velada, tornando seres humanos invisíveis, excluídos em nosso cotidiano como também nas legislações.

Neste sentido, como a legislação é recente, nos compete a realização de uma pesquisa para identificar como as instituições no território brasileiro estão colocando em vigência as legislações que reconhecem os direitos das pessoas trans*. Assim, a legislação maior, a

\footnotetext{
${ }^{3}$ De acordo com Oliveira (2018) a noção de cisgeneridade foi proposta pela Transexual Julia Serrano em 2007 na obra "Whipping Girl: A transexual woman on sexism and the Scapegoating of femininity" a partir do exercício de analisar a origem da terminologia -trans. A abreviação de cisgênero/a é cis. Assim, um sujeito cis é aquele que segue a norma imutável, fixa e cristalizada de gênero. Em outras palavras, a cisgeneridade indica a existência de uma norma regulatória de gênero, ou seja, os sujeitos Cis vivenciam suas expectativas de papeis sociais de acordo com o sexo biológico.
} 
Constituição Federal (1988), destaca, de maneira ampla, que todos os indivíduos, independentemente de sua raça, cor, sexo, etnia são iguais perante a lei, sem distinção de qualquer natureza, garantindo a todos os brasileiros e aos estrangeiros que moram no Brasil o direito à vida, à liberdade, à igualdade, à segurança e à propriedade.

Em continuidade, o mesmo documento, no artigo 23, expressa que "é competência comum da União, dos Estados, do Distrito Federal e dos Municípios, proporcionar os meios de acesso à cultura, à educação e à ciência" para qualquer indivíduo. Sendo a educação "é direito de todos e dever do estado" e em relação ao ensino nos é permitido destacar dois princípios descritos no artigo 206: "igualdade de condições para o acesso e permanência na escola" e "pluralismo de ideias e de concepções pedagógicas, e coexistência de instituições públicas e privadas de ensino" (BRASIL, 1988).

Com isto, cabe destacar que as políticas públicas para as pessoas trans*, de maneira específica, surgiram a partir da Constituição Federal como um direito de todos, mas obtiveram resultados mais afincos a partir dos anos 90. A partir deste momento, graças às lutas de movimentos sociais, começaram a surgir legislações especificas em âmbito municipal e estadual. Neste artigo, nos interessa pensar em como as escolas estão recebendo e propondo políticas de legitimação destas subjetividades em seu cotidiano. Para tal, algumas questões foram suscitadas: Afinal, quem são os/as trans* em nossas escolas? Como propiciar uma Educação escolar na perspectiva inclusiva? Há documentos que espelham e defendem a discussão sobre gênero e sexualidade nas escolas? Na próxima seção defendemos que receber, reconhecer e inserir sujeitos trans* nas escolas é uma questão de justiça social e curricular.

\section{Corpos transexuais nas escolas: por uma questão de justiça social}

Estamos cientes que, nas últimas décadas, diversos sujeitos sociais estão ingressando nas escolas. $\mathrm{Na}$ contemporaneidade, estas instituições estão sendo chamadas a assumir uma série de tarefas e responsabilidades assim como a atender diversas demandas sociais. Dentre os novos sujeitos que buscam seu espaço nas escolas destacamos os/as transexuais.

Logo, torna-se necessário repensar os currículos escolares dentro deste novo escopo. Para Moreira e Candau (2007), o currículo constitui um dispositivo em que se refletem as relações (por vezes tensas) entre sociedade e escola, cercado por saberes, práticas socialmente construídas, atrelados aos conhecimentos científicos, como também aos discursos dominantes 
e discursos subjugados. De acordo com Silva Junior (2014), os currículos de gênero, sexualidades, masculinidades, raça e classe social são os diferentes espaços/ tempos onde sujeitos interagem; as ações escolares, as ações culturais e as tecnologias (arquitetura, livros didáticos, vestimentas, músicas, meios midiáticos etc.). Esses são significados na cultura, ensinam e regulam o corpo, produzindo subjetividades e arquitetando formas e configurações de como se viver em sociedade. Nesse contexto, o currículo é o lócus onde se concentram e se desdobram lutas em torno de diferentes significados sobre o social e o político.

É por meio do currículo, concebido como elemento nuclear da política educacional, que os distintos grupos sociais - especialmente os dominantes - expressam sua visão de mundo, seu projeto social e suas "verdades" (SILVA JUNIOR; MOREIRA, 2010). Sendo assim, problematizar esse espaço pode ser o caminho inicial no processo de formação de novas subjetividades que não se conformam com normas opressoras marcadas no dia a dia de nossas escolas e no fazer diário da maioria de professores/as.

Desta forma, acreditamos que pensar em um currículo inclusivo, associado às subjetividades de cada indivíduo, seria uma questão de justiça social. Para Fraser (2009, p. 17), pensar em justiça social requer organizar "arranjos sociais que permitam que todos participem como pares na vida social”. Para tal, ela defende que a concepção de justiça deve ser derivada das tensões entre as políticas de reconhecimento e redistribuição. De acordo com a autora: "Do ponto de vista distributivo, portanto, a justiça requer política de redistribuição. Do ponto de vista do reconhecimento, em contraponto, a justiça requer uma política de reconhecimento" (FRASER, 2002, p.12). Contudo, devemos ressaltar que em estudos mais recentes, Fraser (2007) incluiu um outro aspecto "a participação", destacando a exigência de sua intensificação na luta política pela justiça.

Neste aspecto, a propostas de Fraser (2002, 2007) dialogam com o que Connell (1997) defende por justiça curricular. Desta maneira, as ideias das autoras podem potencializar as discussões que vislumbram a necessidade das escolas receberem e reconhecer e legitimar os sujeitos trans* em seus cotidianos.

Connell (1997), em seus escritos, relata que a justiça curricular deve estar pautada em três princípios. O primeiro afirma que a justiça social deve mudar seu ponto de partida, trazendo para debate os interesses dos "menos favorecidos", criando projetos/currículos “contra-hegemônicos" que inclua nesta proposta o que é definido como currículo global, mas que garanta a todos o acesso a métodos e descobertas científicas. 
O segundo princípio diz respeito à participação e ao processo de escolarização comum para todos os estudantes, cujos sistemas de ensino, em suas declarações de objetivos, proclamam, em geral, que estão preparando futuros cidadãos para a participação em uma democracia. Não é possível uma democracia em que alguns "cidadãos" recebam apenas as decisões que outros tomaram. Assim sendo, o currículo deve valorizar as experiências de todas cultura (CONNELL,1997). O terceiro e último princípio descrito assinala que o currículo deve estar articulado com a produção histórica de igualdade.

Nesta perspectiva, tendo como base as especificidades de se pensar um currículo subjetivo, Moreira e Candau (2003) nos sugerem que a concepção de justiça curricular se amplie e se compreenda como a proporção em que as práticas pedagógicas incitam o questionamento às relações de poder que, no âmbito da sociedade, contribuem para criar e preservar diferenças e desigualdades. De acordo com as afirmações do autor e autora mencionados, surgem a problematização: será possível reduzir na escola e na prática social os atos de opressão, preconceitos e discriminações? Na próxima seção propomos uma reflexão sobre a legislação que reconhece e legitima os direitos trans* nas escolas.

\section{Entre as dificuldades e as leis que legitimam os direitos trans* nas escolas}

Com esta lógica, ao citar na problematização escola e prática social, é-nos cabível analisar o que a Lei de Diretrizes e Bases da Educação Nacional de 1996, conhecida como LDB, prevê sobre educação que corrobore para o desenvolvimento dos seres humanos, principalmente para eliminação de atos considerados opressores e discriminatórios. Tal documento decreta no seu artigo $1^{\circ}$, inciso $2^{\circ}$ que a educação deve abranger os processos formativos, buscando o desenvolvimento na "vida familiar, na convivência humana, no trabalho, nas instituições de ensino e pesquisa, nos movimentos sociais e organizações da sociedade civil e nas manifestações culturais". Igualmente determina que a educação escolar deve estar vinculada ao "mundo do trabalho e à prática social” (BRASIL, 1996).

Esta análise garante que a escola é lugar de debate, esclarecimento sobre o que é discutir gênero no espaço escolar, cujas propostas e fazeres docentes estejam atreladas a uma educação em processo de inclusão que possibilite a convivência humana no dia a dia de nossas escolas e na prática social, isto quer dizer: que contribua para o respeito as diferenças e as relações sociais. A LDB (1996) no capítulo II, seção I propõe que a educação básica, que atende da Educação Infantil ao Ensino Médio, deve assegurar aos educandos o exercício da cidadania. Os currículos da educação em geral devem abranger o estudo da língua portuguesa, 
da matemática, "o conhecimento do mundo físico e natural e da realidade social e política, especialmente do Brasil" (BRASIL, 1996).

De natureza igual, o ensino da arte, destacando as expressões regionais, como também o ensino da História do Brasil, levando em consideração as diferentes culturas e etnias para a formação do povo brasileiro, a educação física, o ensino da língua inglesa a partir do sexto ano do Ensino Fundamental. Em seu sétimo parágrafo, a legislação em vigor detalha: “A integralização curricular poderá incluir, a critério dos sistemas de ensino, projetos e pesquisas envolvendo os temas transversais [...] de que trata o caput" (BRASIL, 1996, grifo nosso). No nono parágrafo LDB considera que conteúdos que abordam temáticas sobre direitos humanos e a "prevenção de todas as formas de violência contra a criança e o adolescente serão incluídos, como temas transversais, nos currículos escolares” (BRASIL, 1996, grifo nosso).

Para a elaboração de currículos, projetos escolares, planos de ensino e de aula, o Ministério da Educação, após a LDB, ao citar "temas transversais", lançou, em 1997, os Parâmetros Curriculares Nacionais - PNCs (BRASIL, 1997) sem caráter obrigatório ${ }^{4}$. Estes têm a finalidade de orientar a educação brasileira na organização do ensino e conteúdos. Os PCNs contemplam as diversas áreas do conhecimento: língua portuguesa, matemática, ciências naturais, história, geografia, arte, educação física e temas transversais que contemplam a área da ética, pluralidade cultural, orientação sexual, meio ambiente e saúde (BRASIL, 1997, 1998).

O volume 10, intitulado "Pluralidade Cultural e Orientação Sexual" de temas transversais é exclusivo à discussão sobre orientação sexual gênero, sexualidades LGBTIQ+ na escola. Estes temas perpassam o fazer docente e a cultura escolar, cuja discussão é regulamentada como tema transversal desde a LDB e resgata as discussões iniciais nas Diretrizes para uma Política Educacional em Sexualidade (BRASIL, 1994), documento não citado na LDB, mas que há devidas articulações com o PCNs - Orientação sexual (BRASIL,1997).

Há potencialidades na execução deste trabalho para uma educação em processo inclusivo que busque a diminuição das angústias dos estudantes frente à sua sexualidade e também para que se rompa com os discursos estereotipados, preconceituosos, discriminatórios acerca da discussão sobre gênero e o anular as pessoas trans* nos sistemas públicos e privados

\footnotetext{
${ }^{4}$ É relevante destacar que a nova Base Nacional Curricular Comum homologada em 2017 não contempla estas discussões em sua plenitude.
} 
de ensino. Diante dos inúmeros desafios do respeito ao público LGBTQI+, especificamente a população trans* em nossas escolas, para contribuir com o enfrentamento destas dificuldades e o reconhecimento desses sujeitos, o Ministério da Saúde lançou o folheto: “A travesti e o Educador: respeito também se aprende na escola ${ }^{5}$,

\section{Figura 1: A travesti e o educador}

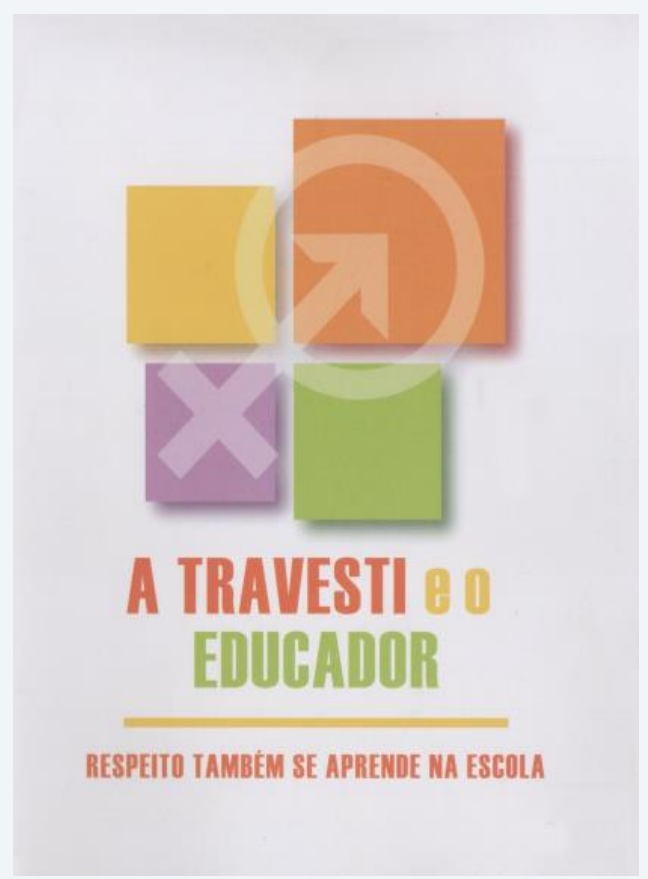

Fonte: Biblioteca Virtual em Saúde (2010).

Figura 2: Conteúdo do folder

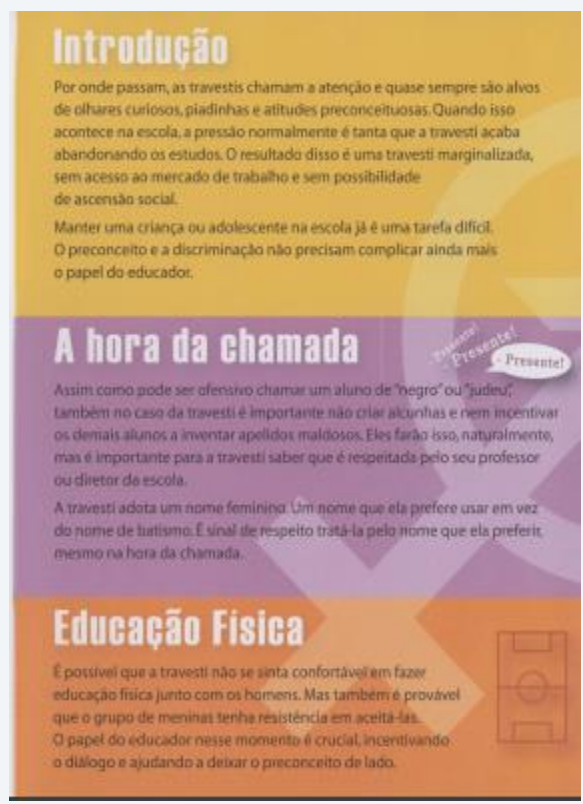

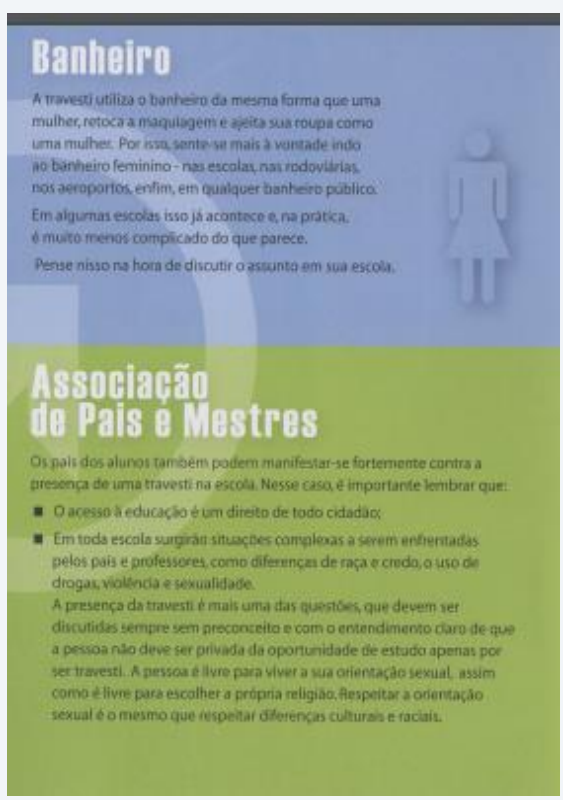

${ }^{5}$ Disponível em: http://bvsms.saude.gov.br/bvs/folder/10006000018.pdf. Acesso 18 set. 2018. 
Fonte: Biblioteca Virtual em Saúde (2010)

Na publicação realizada pelo Ministério da Saúde, são apresentadas as principais demandas das pessoas trans* nas escolas. $\mathrm{O}$ folder evidencia que as travestis chamam a atenção por onde passam, promovendo olhares de curiosidade, atitudes e piadas preconceituosas. Tal material apresenta de como o (a)_ professor(a) deve realizar a hora da chamada e a inclusão do nome social, como promover que o/a travesti se sinta à vontade nas aulas de Educação Física, o uso do banheiro e a parceria entre família e escola para lidar com o desafio de favorecer uma Educação escolar na perspectiva inclusiva, sem acepção de pessoas.

É relevante destacar a importância deste material, uma vez que a transexualidade é pouco conhecida pelos membros da comunidade escolar (diretor/a, professores/as, funcionários/as). Assim, o/a transgênero acaba sendo visto como um homossexual. Lanz (2015, p. 248) afirma que "o aluno transgênero é apenas um aluno homossexual que insiste em usar roupas do gênero oposto". Com isso, ele/ela sofre uma série de preconceitos e não tem acesso às políticas e à justiça social.

O uso do nome social é uma dificuldade enfrentada por sujeitos trans* nas escolas, já que demanda a necessidade de utilização de um nome que se adeque às subjetividades correspondestes, independente das questões biológicas. O nome social é aquele pelo qual sujeitos autodenominados trans* optam por ser chamados cotidianamente, refletindo sua expressão de gênero, em detrimento ao seu nome de registro civil, dado em consonância com o gênero e/ou o sexo atribuídos durante a gestação e/ou nascimento (SILVA JUNIOR, 2016). Para garantir sua utilização existem diversos dispositivos jurídicos em âmbito federal, estadual e municipal. Para efeito de nossa pesquisa, ressaltamos que o município de Duque de Caxias não possui uma legislação especifica. Todavia, a Portaria 1.612, publicada em 21 de novembro de 2011 que

[...] autoriza e garante nos estabelecimentos de ensino o uso do nome social conforme os interesses da pessoa solicitante, a mesma indica: "o direito à escolha de tratamento nominal nos atos e procedimentos promovidos no âmbito do Ministério da Educação.", entendendo por nome social "aquele pelo qual essas pessoas se identificam e são identificadas pela sociedade" (BRASIL, 2011, p. 67).

Ainda sobre o uso do nome social, as pesquisas desenvolvidas por Grossi, Oliveira e Silva (2017) mencionam, com base no levantamento realizado pelo Instituto Nacional de 
Estudos e Pesquisas Educacionais Anísio Teixeira - INEP, que houve um aumento em 46\% o número de travestis e transexuais que utilizaram o nome social no Exame Nacional do Ensino Médio - Enem de 2016. Ou seja, 408 pessoas usaram o nome social no período de 2016, enquanto que, em 2015, somente 278 pessoas trans* utilizaram seus respectivos nomes sociais.

O banheiro que é um espaço muito complicado nas escolas. A divisão por gênero e a vigilância destas normas dificultam o acesso a este por pessoas trans*. A resolução $\mathrm{n}^{\circ} 12$, de 16 de janeiro de 2015 "estabelece parâmetros para a garantia das condições de acesso e permanência de pessoas travestis e transexuais/ - e todas aquelas que tenham sua identidade de gênero não reconhecida em diferentes espaços sociais - nos sistemas e instituições de ensino, formulando orientações quanto ao reconhecimento institucional da identidade de gênero e sua operacionalização" (BRASIL 2015). Com isso, o uso dos banheiros, vestiários e demais espaços separados por gênero, de acordo com a identidade de cada sujeito, podem ser exemplificados com a fotografia (Figura 3) da placa de um banheiro público em um parque no centro de São Paulo.

Figura 3: Banheiro do separado por gênero

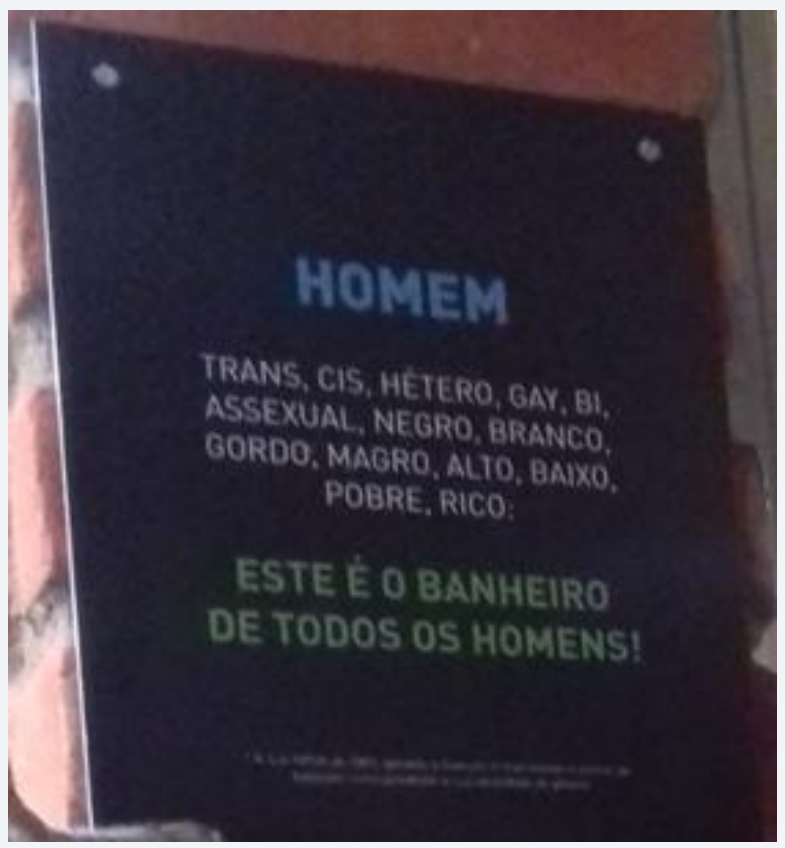

Fonte: Arquivo pessoal (AGUIAR, 2016).

Como neste exemplo, cabe às escolas e espaços públicos repensarem sua utilização, com finalidade de contemplar todos os sujeitos. Retomando as imagens do folheto elaborado 
pelo Ministério da Saúde (Figura 1; Figura 2), podemos perceber que, na prática, tais mudanças podem ser muito menos complicadas do que parece. Porém, a prática de banheiros como o da Figura 3 acima posta, ainda é raridade na realidade das nossas escolas e espaços públicos.

Em paralelo a este assunto, o uso do uniforme é outro grande demarcador de gênero. Normalmente, alunos/as trans* não se sentem confortáveis no uso do mesmo, já que este é marcadamente heteronormativo. É importante ressaltar que a Resolução número 11 de 18 de dezembro de 2014 estabelece os parâmetros para a inclusão dos itens "orientação sexual", "identidade de gênero" e "nome social" nos boletins de ocorrência emitidos pelas autoridades policiais no Brasil. Desta forma, os/as estudantes trans* podem escolher o uniforme que melhor atende seus princípios, ou seja, masculinos ou femininos, previsto no artigo $1^{\circ}$ da mesma resolução

\begin{abstract}
A identidade de gênero "a profundamente sentida, experiência interna e individual do gênero de cada pessoa, que pode ou não corresponder ao sexo atribuído no nascimento, incluindo o senso pessoal do corpo (que pode envolver, por livre escolha, modificação da aparência ou função corporal por meios médicos, cirúrgicos ou outros) e outras expressões de gênero, inclusive vestimenta, modo de falar e maneirismos" (BRASIL, 2015).
\end{abstract}

Outra dificuldade muito marcada no cotidiano da escola são as aulas de educação física. Estas podem ser um dificultador para a população trans*, a partir do momento que, ao serem enquadradas em um dos dois polos, feminino e masculino, eles/elas podem não se sentir confortáveis nestas divisões, principalmente pelo fato de serem rejeitados/as por meninos e não se sentirem confortáveis com as meninas.

Em relação à Associação de pais e mestres, o folheto do MEC (Figura 1 e 2) destaca que os/as responsáveis por alunos/as podem se posicionar contra a presença de alunos/as trans* nas escolas. No entanto, o próprio documento afirma que o acesso à escola é um direito de todos/as. Assim, a presença destas pessoas deve ser discutida no âmbito do coletivo afim de que as mesmas não sejam privadas de seus direitos.

Podemos marcar a incongruência de haver uma lei e uma resolução, além de um folheto nacionais que pedem que haja uma Educação escolar na perspectiva inclusiva, mas que, para tanto, nos dois pontos acima citados, esta depende de uma conscientização de professores/as como protagonistas na luta contra o preconceito. Apontamos essa falha devido ao fato de Grossi, Oliveira e Silva (2017, p.190) terem realizado uma relevante investigação sobre como os cursos de formação de professores/as estão discutindo estas questões e 
preparando os/as futuros/as profissionais para o enfrentamento destas questões. Foram investigados 1.550 cursos de Pedagogia, Normal Superior e cursos dos Programas Especiais de Formação Pedagógica de docentes. De acordo com os autores/as, os/as professores/as "não têm sido preparados em sua formação acadêmica para lidar com alunos transexuais, uma vez que em nenhuma das grades curriculares analisadas há a incorporação de disciplinas que abordem especificamente o tema transexualidade”.

$\mathrm{Na}$ próxima seção, apresentaremos os sujeitos desta pesquisa, que teve como motivação exatamente os impasses e as incongruências até aqui apresentadas neste artigo, suas histórias e realidades transgressoras, destacando as potencialidades das escolas em criar um ambiente possível para o desenvolvimento de uma justiça curricular e social.

\section{Transgredindo no cotidiano escolar: ouvindo vozes e conhecendo histórias}

No início deste trabalho delimitamos a natureza do mesmo, porém cabe, neste momento, retomamos os paradigmas adotados em nosso empreendimento. No que tange à natureza, optamos pela pesquisa qualitativa, uma vez que esse tipo de investigação "busca uma maior compreensão dos significados e características presentes no cotidiano dos participantes" e considera sua "subjetividade, emoções, valores e crenças" (CARRANCHO, 2005, p. 57).

Para tentar atingir o nosso objetivo, nossa busca por escolas foi longa. Visitamos várias delas, conversarmos com diversos/as professores/as, porém sempre caíamos na mesma situação: os alunos e alunas trans* tinham de se adaptarem às regras heteronormativas postas. Após diversas tentativas, encontramos alunas trans* que estudam em escolas que tentam criar um ambiente positivo de convívio, assim como pessoas que vivenciam o cotidiano escolar e são sensíveis à causa. A seguir apresentamos os sujeitos que narram suas histórias e que, em determinada medida, desestabilizam o cotidiano escolar.

Lexie, 18 anos é estudante do $3^{\circ}$ ano do ensino médio da rede pública estadual de Belford Roxo (outro município da baixada fluminense). Ela nos contou sobre suas relações sociais nessa escola, principalmente depois que realizou sua transição. A entrevista aconteceu no dia 01 de julho de 2018 em Belford Roxo (município da baixada fluminense- Rio de Janeiro) teve a duração de aproximadamente 2 horas.

Flávia é orientadora educacional. A entrevista aconteceu no dia 18 de julho de 2018, quando conhecemos a escola que ela trabalha no primeiro distrito de Duque de Caxias, aqui 
denominada "Escola para a Vida". A duração de nossa conversa foi de aproximadamente 1 horas.

A entrevista com Antônia, orientadora educacional de outra escola do segundo distrito de Duque de Caxias, aconteceu na própria unidade escolar no dia 20 de agosto de 2018. Neste espaço aqui denominado como "Escola Experimental", estudam três alunas trans*, dentre elas Safira com a qual realizamos conversas informais. Permanecemos aproximadamente duas horas e meia nesta unidade escolar entre a entrevista, conversas informais e conhecimento do espaço. Já com Rachel ${ }^{6}$ que é aluna de uma escola federal de ensino médio, as conversas aconteceram por telefone e Whatsapp.

Para a geração de dados, realizamos entrevistas ${ }^{7}$ semiestruturadas, observação do cotidiano das escolas e anotações de conversas informais consideradas significantes. As participantes das entrevistas foram informadas sobre os objetivos da pesquisa, sobre a divulgação dos resultados para fins de difusão do conhecimento científico, bem como sobre a confidencialidade do material com informações sobre os sujeitos. É relevante ressaltar que interessou-nos observar e ouvir as vozes das pessoas que "vivem as práticas" (MOITA LOPES, 2012). Queríamos ouvir as vozes e conhecer as histórias de quem vivencia o cotidiano escolar. Com isso, apesar de Santos $(2003,2008)$ nos mostrar que a escola é plural, que todos devem conviver com as diferenças e romper com estereótipos, não foi o que percebemos em um primeiro momento. Os relatos abaixo apresentados de Lexie e Flávia mostram como este ambiente pode ser hostil aos homossexuais. A escola como ambiente segregador marca lembranças:

$\mathrm{Na}$ escola, com 14 anos, eu pedia para me chamarem de 'Same', porque não me sentia à vontade sendo chamado de 'Samuel'. Só que meus professores falavam que não podiam me chamar assim... Algumas pessoas do meu círculo de amizades diziam que não podiam me chamar por outro nome... Eu sempre fui bem afeminado... bem feminina. Quando nova, sofri muito xingamento na escola. Os colegas demonstravam mais preconceito com o 'Same'... Eu sofri muito preconceito. Falavam: “Aquela bicha!", que eu tinha doença (Lexie).

$\mathrm{Na}$ verdade, eu acho que as duas alunas [Carla e Rogéria] sofrem menos com as brincadeiras homofóbicas do que alguns alunos homossexuais que temos aqui. Quando o homem é muito afeminado, sofre mais com o preconceito.

\footnotetext{
${ }^{6}$ Destacamos que a entrevistada é membro do grêmio desta escola e foi uma das responsáveis pela organização e realização da semana da diversidade. Neste evento, ela foi a responsável por pensar e organizar as discussões sobre os sujeitos trans*.

${ }^{7}$ Afirmamos, também, que as entrevistas foram gravadas e transcritas pelos autores e autora.
} 
No caso delas, elas são vistas como mulheres pela maioria (Flávia, orientadora educacional).

As falas nos permitem recorrer a Britzman (1996, 2001), Sullivan (1996) e Miskolci (2012) que nos mostram o ambiente escolar é um dos mais perversos para pessoas cuja a orientação sexual seja diferente da heteronormativa. O terrorismo cultural (MISKOLCI, 2012) foi um recurso utilizado pelos colegas de escola para mostrar como opera o heterossexismo e, ao mesmo tempo, para impor a heterossexualidade compulsória. Estes fatos marcam a necessidade de as escolas realizarem discussões sobre as múltiplas sexualidades, ao mesmo tempo em que destaca o protagonismo dos/das alunos/as do grêmio da escola federal.

Em relação à necessidade de trazer à baila as discussões sobre as questões LGBT nas escolas, Rachel nos conta que:

A ideia de fazer a semana da diversidade veio justamente por causa dos professores despreparados para abordar o assunto LGBT. Nos viamos que as aulas eram totalmente heteronormativas e que ao perguntar coisas voltadas para a comunidade LGBT, eles não sabiam responder. É importante discutir temas LGBT, ainda mais aqui na escola, que é muito LGBTfobica. Então era essencial promover o debate; A letra T é muito invisibizada no meio da comunidade LGBT, portanto era muito importante dar voz a eles.

Conforme o relato de Rachel, ela destaca a importância de discutir com a equipe de professores/as gênero e sexualidade na escola, neste sentido torna-se o ambiente escolar inclusivo para todos/as rompendo com os discursos heteronormativos, daí a necessidade dos temas transversais - pluralidade cultural e orientação sexual ser um eixo norteador da prática educativa, com a finalidade de promover o debate entre os estudantes e professores reconhecendo que tal temática é um processo. Todavia, discutir com os/as alunos/as na escola é

[...] propiciar informações atualizadas do ponto de vista científico e ao explicitar e debater os diversos valores associados à sexualidade e aos comportamentos sexuais existentes na sociedade, possibilita ao aluno desenvolver atitudes coerentes com os valores que ele próprio eleger como seus (BRASIL, 1997, p. 122).

Deste modo, conseguiremos garantir o acolhimento para os/as alunos/as trans*, dúvidas serão trazidas ao debate, esclarecimento do que é sexualidade afim de estabelecer uma cultura escolar inclusiva onde zele pelo respeito a essência e subjetividade de cada ser humano, independente do seu gênero, raça, cor ou etnia. Assim, pensando nos casos das trans*, defendemos que o trabalho de acolhimento, de promoção de respeito e justiça social 
deve ser promovido pelas escolas, onde a abertura para conversa seja a proposta inicial com professores em sequência com os/as alunos/as como apresentou Rachel.

Cabe a estes espaços e seus sujeitos sociais reconhecerem e promoverem a inteligibilidade de todos os corpos. Corpos estes que não somente se aproximam das normas, como nossas entrevistadas expuseram, já que fica marcado nos discursos ouvidos que nas escolas elas sofreram maior violência e preconceito quando eram confundidas com homossexuais. Até porque elas não são homossexuais, elas são trans*, tanto que a Secretaria municipal de Saúde elaborou um folder de como os professores podem lidar com essas pessoas. Assim, trazer estas questões para as escolas é vivenciar a justiça curricular (CONNELL, 1997). É neste sentindo que coadunamos com Moreira e Candau (2003) quando afirmam que as práticas pedagógicas devem incitar os questionamentos sobre as relações de poder no âmbito da sociedade e como elas estão contribuindo para a preservação das desigualdades.

Como visto na seção anterior, o nome social é uma importante questão e permite que os sujeitos se adéquem às subjetividades correspondentes, independentemente das questões biológicas. A legislação brasileira (BRASIL, 2011) apresenta o respaldo legal para que as escolas adotem o nome social. Contudo conforme os depoimentos abaixo podemos perceber que ainda estamos em processo. No primeiro de depoimento, a aluna Lexie passou pelo processo de transição na escola. A sensibilidade inicial de uma professora conseguiu fazer com que o grupo de professores/as da turma buscassem soluções para tratar a aluna pelo nome social. Já no segundo depoimento, percebemos os caminhos percorridos pela orientadora educacional para a utilização do nome social, e igualmente o trabalho de sensibilização da comunidade escolar, fazendo com que professores e professoras fosse aderindo, gradualmente, ao nome social.

Chegar na escola foi um pouco difícil, mas foi até engraçado, porque eu já cheguei com o decreto que pesquisei. Mostrei para professora de história e ela disse: "Eu já sabia", e falou meu nome de registro. Perguntou: "Já posso te chamar por outro nome? Qual seria?" Eu falei: "Me chama de Lexie. Eu me sinto contemplada por este nome." No dia seguinte, fiquei sabendo que a professora de história tinha conversado com a pedagoga e outros professores. Fui bem aceita pelos professores. Eles demonstraram empatia comigo e me trataram bem. Os dois diretores, o antigo e o novo que entrou, tiveram empatia... me tratavam bem. Só um professor de educação física que falou: "Mas este não é seu nome." Eu disse que era o nome que eu me sentia confortável. Ele respondeu: "Ah, tá! Mas quando vier a chamada e este não for seu nome, eu não vou falar, vou te chamar pelo nome que está na chamada." Passou uma, duas semanas e ele me chamava de Lexie, 
normalmente. Quando chegou a chamada, eu fiquei receosa. Se ele me chamar por aquele nome, vou passar constrangimento. Na verdade, ele respeitou e eu fiquei bem surpreendida. Não esperava. Na chamada ainda não tem meu nome social, mas tem o nome a lápis ao lado. Eu ainda não entrei com o processo (Lexie).

Para resolver a questão do nome social, fazemos da seguinte maneira: não podemos mexer no nome de registro, então, assim que elas chegam, a secretaria encaminha para orientação educacional. Nós conversamos com elas e colocamos nas fichas, diários o nome social. Como a Rogéria foi a primeira, combinei com ela que só a chamaríamos pelo nome que ela escolheu. No primeiro dia, fui à sala e apresentei a Rogéria. Apesar de quase todos se conhecerem na comunidade, achei que seria importante dar respaldo. A Carla chegou depois. Tivemos dificuldade com alguns professores. Alguns, no princípio, relutaram em aceitar. Uma disse que não conseguia chamar o Junior de Rogéria. Precisei lembrar-lhe de que o Junior tinha evadido da escola por não se adaptar e nós não tínhamos feito nada. Nos diários, para facilitar, fazemos assim: colocamos o nome social e, entre parênteses, o do registro ao lado. De um modo geral, tem dado certo (Flávia).

Concordamos com Connell (1997) quando ela afirma que o primeiro princípio para se pensar em justiça social é trazer os menos favorecidos para o debate, é criar projetos contra hegemônicos que incluam estes sujeitos. Assim, sendo o nome, a marca que identifica o sujeito em primeiro contato social, dar aos sujeitos trans* a possibilidade de utilizarem o nome social também é uma questão de justiça curricular.

No entanto, Antonia nos mostrou a dificuldade de propor o uso do nome social pela escola quando os alunos e alunas são menores de idade.

Olha temos que ter muito cuidado com a utilização do nome social, primeiro porque é uma lei estadual nossa escola é municipal e o município de Duque de Caxias não possui legislação neste sentido. Segundo, por que quando são menores, os pais têm que autorizar a utilização. Aqui na escola tivemos uma aluna, a Jenifer, era uma menina que não se via como tal, se via como menino. Por isso, tinha tido diversos problemas com a mãe, chegou até apanhar aqui na porta da escola, segundo a mãe "para aprender gostar de meninos". Bem, quando ela foi para o para o ensino médio, cortou os cabelos e disse que queria ser chamada de João. Segundo os amigos dela, todos chamavam pelo nome escolhido, inclusive alguns professores. Só que a mãe não sabia disto. Quando ficou sabendo, foi à escola e fez um escândalo. Assim, só podemos fazer isto com a autorização dos pais. No caso de nossos alunos, eles são menores 16 e 17 anos. Como vem de brincos, maquilagem, achamos complicado os nomes de Caio e Antonio nos diários. Chamamos os pais para conversar, mas não compareceram na escola.

A fala acima destaca os limites da escola e a necessidade de caminhar junto com a família e/ou responsáveis pelos/as alunos/as. Conforme a legislação vigente (BRASIL,1994, 1996,1988), a escola pode e deve trabalhar as questões de sexualidades, buscar com que o 
corpo discente encontre um espaço de acolhimento e reconhecimento. Contudo, no caso de crianças ou menores, a participação dos responsáveis é de extrema importância. Assim, apesar de a legislação reconhecer e autorizar a utilização do nome social, no caso de menores, a escola necessita da participação da família. Sem a mesma, pode ocorrer o que a aluna Safira nos contou em conversa informal:

Em mesma fiz meus cabelos, agora só venho para escola assim, vestido como mulher. Eu sou mulher, um dia vou fazer operação, pode acreditar.... Eu não venho muito a escola. Aqui não é fácil... mas tem professor que é legal...não fala o nome verdadeiro da gente e até chama de moça. É muito ruim ser chamado de Caio e estar de brinco e batom.

A aluna estuda na escola que Antônia é orientadora. Apesar de concordar que é constrangedor, a orientadora nos afirmou que não pode fazer nada: "a família não é presente". Isto impossibilita qualquer ação da escola, por melhor intencionada que esteja. A orientadora relatou que conversa com o corpo docente e funcionários para evitar chamar pelo nome de batismo e pelo nome feminino, para tentar utilizar ao longo das conversas substantivos comum de dois gêneros, apenas para amenizar a situação e aguardar a vinda da família ou que a estudante complete a maioridade.

Pensando em currículo enquanto um conjunto de artefatos (SILVA JUNIOR, 2014), podemos destacar que o uso dos uniformes, acessórios e maquilagem é outra questão para a escola que busca normatizar corpos. Fato que se torna outro problema para os/as alunos/as trans*.

Na minha escola todos alunos e alunas tem que usar a blusa do Governo do Estado, pode ir de calça, bermuda ou saia jeans. A direção não liga para maquilagem ou enfeites. Eu uso uniforme como todos, normalmente calça jeans. Não gosto deste tipo de saia jeans, gosto de saia tipo cigana. Como sou discreta, uso brinco pequenos e pouca maquilagem. Nesta escola que estudo agora eles nunca reclamaram de nada nem pediram para mudar o meu jeito (Lexie).

Aqui na escola pedimos para elas usarem a blusa da escola e calça jeans como todos alunos. Elas podem usar maquilagem e brincos. Só uma vez que a Carla veio com pôr de rodelas enormes e muito maquilada, aí eu pedi para se controlar. Mas de um modo geral elas não tem problemas com o uniforme (Flávia orientadora educacional).

Aqui na escola, no turno da noite normalmente não cobramos uniforme. Como não recebemos blusas, não cobramos nem a blusa. Normalmente todos estão de calças ou bermudas. Ainda não conversamos com estas alunas sobre o que elas devem vestir ou não aqui na escola (Antonia, orientadora educacional). 
Apesar da resolução de dezembro de 2014 (BRASIL, 2015) assegurar o direito das/dos alunas/os trans* em relação ao uso do uniforme, as falas acima nos mostram que as orientadoras buscam resolver estas questões muito mais pelo campo da sensibilidade e diálogo do que pela legislação vigente. Neste sentido, concordamos com Lanz (2015) e Grossi, Oliveira e Silva (2017) quando afirmam a falta de conhecimento nas escolas sobre a transexualidade. Assim, ao desconhecerem as leis, os/as gestores/as não podem colocar em práticas possibilidades de reconhecimento das subjetividades.

O banheiro é um espaço de igual embate nas escolas ouvidas. Trata-se de um espaço que demarca gêneros: masculino e feminino. A seguir apresentamos depoimentos nos quais as entrevistadas relatam as alternativas que suas escolas estão tentando buscar para solucionar esta questão.

No caso do banheiro, que é um espaço muito complicado nas escolas, liberamos um banheiro de professores para elas. Assim, elas não têm problema nem com rapazes nem com moças. A chave fica na coordenação de turno. Deixamos claro que caso outro aluno ou aluna sinta necessidade, poderá utilizar (Flávia).

Na minha escola, uso o banheiro perto da coordenação (Lexie).

No turno da noite alunos e alunos usam o banheiro individual que fica no corredor. Isto evita que qualquer aluno ou aluna sofra algum constrangimento (Antonia).

Na escola até dá para ir ao banheiro... Mas eu não gosto... eu só vou ao banheiro no salão da minha tia ou em casa... Na rua eu não gosto (Safira... Conversa informal).

A fala de Safira representa a situação vivenciada por muitas trans*em nossa sociedade. Muitas evitam utilizar banheiros públicos para não passarem por maiores constrangimentos. Assim, a solução encontrada pelas orientadoras educacionais e pelas escolas que visitamos foi a individualização dos banheiros. Dessa forma a criação de banheiros individuais e unissex garante que jovens trans* ou alunos/as que não se sintam confortáveis em banheiros possam vivenciar o direito de realizar suas necessidades fisiológicas como todos outros estudantes do cotidiano escolar.

Tematizar o universo trans* nas escolas, fazer circular novos conhecimentos, ao mesmo tempo receber, acolher alunos/as trans* nas escolas é uma questão de reconhecimento e valorização da diversidade. Rachel destaca como organizou o dia da discussão sobre transexualidade 
Chamamos convidados de diversas áreas de conhecimento para eles falarem para eles falarem de diversas coisas porque além de trans* são pessoas. Então a abordagem deles foi isso de desmistificar a transexualidade e falar quem eles eram (Raquel).

Ao mesmo tempo, Flavia destaca a necessidade de enfrentar desafios e implementar possibilidades de acolhimento

Dizer que a escola precisa prestar atenção nas questões de diversidade é chover no molhado. Na teoria, todos sabemos disto. Todos professores dizem isto, mas a questão é a prática. Trabalho nesta escola há mais de 15 anos. Conheci a Rogéria quando ainda era o Junior. Ele entrou aqui na educação infantil, começou repetir de ano no fundamental 2 e sumiu. Ano passado, voltou como Rogéria, ainda no $6^{\circ}$ ano. Senti que a escola precisava fazer alguma coisa, além de dizer que aceitava a diversidade. Precisava colocar em prática. Este ano entrou a Carla. [...] Aos poucos, estamos nos preparando para receber a diversidade. No caso das trans*exuais, o maior problema que temos está em relação aos espaços da escola, principalmente o banheiro e o nome. Os alunos que são gays e lésbicas... Precisamos trabalhar as questões de respeito, mas isto é de uma forma geral como precisamos trabalhar o racismo, o respeito às deficiências. $O$ trabalho é constante, com professores, alunos, funcionários (Flávia).

Antonia nos conta sobre a necessidade de promover o acolhimento as alunas trans* que hoje estudam na escola experimental

Não é um a questão fácil, temos três alunas transexuais na escola. Nem eu, nem nossos professores e profissionais possuímos formação especifica para trabalhar. A estrutura da escola é esta que vocês estão vendo. O município, a secretaria de educação não possui leis especificas para esta população. Aqui estamos tentando fazer o que é possível. Tentamos acolher e evitar preconceitos e evasão dentro de nossas possibilidades. O nome social não podemos utilizar os responsáveis não comparecem á escola. Conversamos com professores e funcionários para evitar constrangimentos e defende-las de ataques ou brincadeiras de mal gosto. É um longo processo estamos tentando.

Ao longo desta seção apresentamos ações simples promovidas pelas escolas como a adoção do nome social, o oferecimento de banheiros, uso dos uniformes, a discussão da diversidade, conversas com corpo docente e discente contribuíram para a permanência e acolhimento de alunos/as trans*. Defendemos estas ações como uma questão de justiça social. Conforme Fraser $(2002,2007,2009)$ afirma, trata-se da necessidade de permitir que os diversos arranjos sociais participem como pares na vida social. Assim, podemos entender que, ao possibilitar tais ações, as escolas buscam preconizar o reconhecimento e participação destas alunas no cotidiano escolar. Neste sentido, a categoria redistribuição pode garantir a 
entrada de novos conhecimentos sobre estes sujeitos que estão buscando seus espaços no ambiente escolar. Poderia potencializar novas possibilidades de inclusão social, assim como a ampliação do repertório cultural dos/as alunos/as e professores/as articulando redistribuição com reconhecimento no campo curricular, destacamos a importância de valorizar as diferenças culturais, de considerar as diferentes formas de estar no mundo e viver a vida. Poderia permitir que as escolas trabalhem as questões relativas as desigualdades sociais.

Ainda de acordo com Fraser a categoria participação, articulada à redistribuição e reconhecimento, pode permitir que diferentes atores sociais fossem valorizados pela escola. Neste sentido, estes sujeitos poderiam participar ativamente dos movimentos do cotidiano escolar.

As políticas simples promovidas pelas escolas para além de tentarem promover justiça social, contribuem para possibilitar a qualidade da educação e a justiça curricular (CONNELL 1997). Desta forma, pensando na interseção entre justiça social e justiça curricular no desenvolvimento de um trabalho que envolva todos os sujeitos em processo de escolarização comum, estaremos vislumbrando a construção de um currículo que valorize as experiências de todas as culturas e certamente contribuindo para a melhoria da qualidade da educação.

\section{Uma escola para todos: considerações finais}

A questão que esteve implícita ao longo deste texto foi como a escola pode se transformar em um espaço de inteligibilidade para corpos trans*. Para tal, apresentamos as narrativas de Lexie, aluna trans* de uma escola estadual, Raquel aluna e membro do grêmio de uma escola pública federal responsável por organizar a semana da diversidade na escola, Safira aluna trans* de uma escola municipal de Duque de Caxias, e de Antônia e Flavia, orientadoras de escolas públicas da rede municipal de Duque de Caxias. Suas histórias nos mostraram que a escola pode, mesmo que com limitações, se tornar um espaço para a legitimação das subjetividades de pessoas trans*.

É relevante destacar que, para atender aos objetivos propostos, buscamos escolas que desenvolviam trabalhos de acolhimento e reconhecimento destas subjetividades. Nosso interesse, ao longo deste texto, foi potencializar as ações relatadas pelos sujeitos ouvidos nesta pesquisa. Ao longo desta encontramos uma série enorme de escolas que não possuíam um olhar atento para esta questão. Naqueles espaços alunos e alunas são obrigados/as a se enquadrarem nas regras e discursos heteronormativos. Não foi proposta desta pesquisa trazer 
estes espaços à baila, mas acreditamos ser necessário, em outro momento, tocarmos e pesquisarmos esse assunto. Nosso desejo foi mostrar o potencial e as possibilidades da escola em promover a justiça tanto social como curricular em um espaço onde diferentes subjetividades o habitam, não se podendo normatizar o como ser e viver no mundo de uma única forma.

\section{REFERÊNCIAS}

AGUIAR, J. F; MAIA, M.V.C.M. "Somos iguais e somos diferentes": olhares dos alunos sobre inclusão no contexto escolar. Pesquisa e Prática em Educação Inclusiva, v.1, n. 1, p. 43-54, 2018.

ALMEIDA, A. Evasão escolar entre travestis é bem maior. Diário de Cuiabá, Cuiabá, 23 maio 2016. Disponível em: http://flacso.org.br/?p=15833. Acesso em: 31 out. 2018.

ANDRÉ, M. E. D. A. de. Estudo de caso em pesquisa e avaliação educacional. Brasília, DF: Liberlivros, 2005.

BRASIL. Constituição da República Federativa do Brasil. Brasília, DF: Senado Federal: Centro Gráfico, 1988.

BRASIL. Diretrizes para uma política educacional em sexualidade. Brasília: Secretaria de Projetos Educacionais Especiais, 1994.

BRASIL. Lei 9.394 de 20 de dezembro de 1996. Estabelece as diretrizes e bases da educação nacional. Planalto. Brasília, DF: 20 dez. 1996. Disponível em:

http://www.planalto.gov.br/ccivil_03/Leis/L9394.htm. Acesso em: 31 out. 2018.

BRASIL. Parâmetros curriculares nacionais para o ensino fundamental: introdução. Brasília, DF: Ministério da Educação, 1997.

BRASIL. Parâmetros curriculares nacionais para o ensino fundamental: pluralidade cultural e orientação sexual. Brasília, DF: Ministério da Educação, 1998.

BRASIL. Ministério da Educação. Portaria no 1.611, de 17 de novembro de 2011. Brasília, DF: 17 dez. 2011. Disponível em: http://www.in.gov.

br/visualiza/index.jsp?data $=21 / 11 / 2011 \&$ jornal $=1 \&$ pagina $=68 \&$ totalArquivos $=168$. Acesso em: 20 jul. 2018. 
BRASIL. Resolução n. 12, de 16 de janeiro de 2015. Secretaria de direitos humanos conselho nacional de combate à discriminação e promoção dos direitos de lésbicas, gays, bissexuais, travestis e transexuais. Lex. Brasília, DF: 16 jan. 2015. Disponível em: http://www.lex.com/legis_26579652_resolucao_N_12_DE_16_DE_JANEIRO_DE_2015.asp x. Acesso em: 20 jul. 2018.

BRITZMAN, D. Curiosidade, sexualidade e currículo. In: LOURO, G. L. (org.). O corpo educado: pedagogias da sexualidade. Belo Horizonte: Autêntica, 2001. p. 83-112.

BRITZMAN, D. O que é esta coisa chamada amor - identidade homossexual, educação e currículo. Educação e Realidade, Porto Alegre, v. 21, n. 1, p. 71-96, 1996.

CANEN, A; IVENICKI, A. Metodologia da pesquisa: rompendo fronteiras curriculares. Rio de Janeiro: Ciência Moderna, 2016.

CARRANCHO, A. Metodologia da pesquisa aplicada à educação. Rio de Janeiro: Waldyr Lima, 2005.

CONNELL, R. W. Escuelas y justicia social. Madrid: Morata, 1997.

FRASER, N. A justiça social na globalização: redistribuição, reconhecimento e participação. Revista Crítica de Ciências Sociais, Lisboa, n. 63, p. 7-20, 2002.

FRASER, N. Mapeando a imaginação feminista: da redistribuição ao reconhecimento e à representação. Estudos Feministas, Florianópolis, v. 15, n. 2, p. 291-308, 2007.

FRASER, N. Reenquadrando a justiça em um mundo globalizado. Lua Nova, São Paulo, n.77, p. 11-39, 2009.

GIL, A. C. Métodos e técnicas de pesquisa social. 6. ed., São Paulo: Atlas, 2009.

GROSSI, M. G. R.; OLIVEIRA, E. S.; SILVA L. C. Transexualidade na formação do professor da educação básica: desvelando a realidade brasileira. Revista Humanidades, Fortaleza, v. 32, n. 2, p. 180-192, 2017.

LANZ, L. O corpo da roupa: a pessoa transgênera entre a transgressão e a conformidade com as normas de gênero. Uma introdução aos estudos transgêneros. Curitiba: Transgente, 2015 .

MISKOLCI, R. Teoria queer: um aprendizado pelas diferenças. Belo Horizonte: Autêntica, 2012.

MOITA LOPES, L. P. da. Prefácio: Linguagem e escola na construção de quem somos. In: FERREIRA, A. de J. (org.). Identidades sociais de raça, etnia, gênero e sexualidade: práticas pedagógicas em sala de aula de línguas e formação de professores/as. São Paulo: Pontes, 2012. p. 9-12. 
MOREIRA, A. F. B.; CANDAU, V. M. F. Currículo, conhecimento e cultura. In: BEAUCHAMP. J.; PAGEL, D.; NASCIMENTO, A. R. (org.). Indagações sobre currículo. Brasília, DF: Ministério de Educação, Secretaria de Educação Básica, 2007.

MOREIRA, A. F.; CANDAU, V. M. F. Educação escolar e cultura(s): construindo caminhos. Revista Brasileira de Educação, Rio de Janeiro, n. 23, p.156-168, 2003.

OLIVEIRA, M. R. G. Transexistências negras: o lugar das travestis e mulheres transexuais negras no Brasil e em África até o século XIX. In: RIBEIRO, P.R.C. et al. (orgs.). Corpo, gênero e sexualidade: resistência e ocupa (ações) nos espaços de educação. Rio Grande: Ed. FURG, 2018. p. 69-88.

SANTOS, M. P. dos. O papel do ensino superior na proposta de uma educação inclusiva. Revista da Faculdade de Educação da UFF, Niterói, n.7, p.78-91, 2003.

SANTOS, M. P. dos. Prefácio. In: SANTOS, M. P. dos; PAULINO, M. M. (Org.). Inclusão em educação: culturas, políticas e práticas. São Paulo: Cortez, 2008. p.7-10.

SILVA JUNIOR, J. A. da. Direitos à meia luz: regulamentação do uso do nome social de estudantes travestis e transexuais nas instituições escolares. Revista da FAEEBA -

Educação e Contemporaneidade, Salvador, v. 25, n. 45, 2016. p. 173-189. Disponível em: https://www.revistas.uneb.br/index.php/faeeba/article/view/ 2293/1599. Acesso em: 01 jul. 2017.

SILVA JUNIOR, P. M. Quando as questões de gênero, sexualidades, masculinidades e raça interrogam as práticas curriculares: um olhar sobre o processo de co/construção das identidades no cotidiano escolar. 2014. 236 f. Tese (Doutorado em Educação) - Universidade Federal do Rio de Janeiro, Rio de Janeiro, 2014.

SILVA JUNIOR, P. M.; MOREIRA, A. F. Periferias, sexualidades e educação para a sexualidade: desafios para as práticas curriculares. In: SOBREIRA, H.G. (org.). Educação, cultura e comunicação nas periferias urbanas. Rio de Janeiro: Lamparina, 2010. p. 21-39.

SILVA JUNIOR, P.M MAIA, M.V.C.M; IVENICKI, A. Homens por vir: reflexões sobre o processo de construção das masculinidades na educação infantil a partir de jogos e brincadeiras. Revista Educação em perspectiva, Viçosa, MG, v.9 n.1 p.67-86

SILVA, R. G. L. B; BEZERRA, W.C.; QUEIROZ, S.B. Os impactos das identidades transgênero na sociabilidade de travestis e mulheres transexuais. Revista Terapia Ocupacional, São Paulo, v. 26, n.3, p 364 -372, 2015.

SOUZA, A. Governo ajudará transexuais a irem para casa. O Globo, Rio de Janeiro, 16 fev. 2012. Caderno O País, p. 14.

SUlLIVAN, A. Praticamente normal: uma discussão sobre o homossexualismo. São Paulo: Companhia das letras, 1996. 


\section{$\underline{\text { SOBRE OS AUTORES }}$}

\section{Paulo Melgaço da Silva Junior}

Pós doutorando em Educação e Doutor em Educação pela Universidade Federal do Rio de Janeiro (UFRJ). Professor da Rede pública Municipal de Duque de Caxias/ Rio de Janeiro. Email:pmelgaco@uol.com.br

\section{ORCID http://orcid.org/0000-0002-4301-9305}

\section{Jonathan Fernandes de Aguiar}

Doutorando em Educação pela Universidade Federal do Rio de Janeiro (UFRJ), bolsista "PROEX", Pesquisador do grupo de pesquisa - Criar e Brincar: o lúdico no processo de ensino-aprendizagem. E-mail: escritorjonathan@ gmail.com

\section{ORCID https://orcid.org/0000-0001-8517-148X}

\section{Maria Vitoria Campos Mamede Maia}

Professora Associada da Faculdade de Educação da Universidade Federal do Rio de Janeiro (UFRJ). Coordenadora do Grupo de Pesquisa LUPEA-PPG. E-mail: mariavitoriamaia.ufrj@gmail.com 